\section{Commentary: Bundled payment models in value-based care: A toe in the (Colombian) water!}

\author{
Michael Mack, MD
}

Healthcare systems worldwide struggle regarding how to deliver optimal healthcare to their citizens while controlling ever spiraling costs. Although the particulars vary from country to country and in different healthcare delivery models, the principles of value-based health care delivery remain constant. Value can be holistically defined as quality divided by cost (both medical and financial). Thus, value is increased by improving quality outcomes, lowering cost, or, optimally, both. Costs can be lowered by decreasing complications, procedure invasiveness, and variability in care.

To address this universally vexing issue in health delivery, Dr Umana, Chief Medical Officer at the largest cardiac care provider in Colombia, describes a unique pilot initiative that demonstrates that institutions can provide improved quality care while controlling costs. ${ }^{1}$ The model involves engaging all stakeholders led by physician champions in a bundled payment program. In this model, providers built trust and partnership with a government payor and they were able to demonstrate that by combining all components of care, including outpatient visits, diagnostic tests, and cardiac surgical procedures, into a single cost bundle, significant cost savings can be realized while achieving a demonstrable improvement in quality outcomes.

In the US, an alternative approach has been taken to the bundled payment model. The Centers for Medicare and Medicare Services has implemented an alternative payment model as a part of their value-based care initiative, the Bundled Payments for Care Improvement (BPCI) initiative. ${ }^{2}$ In these BPCI payment models, hospitals are responsible for all costs incurred from the time of the "anchor

\footnotetext{
From Baylor Scott \& White Health, Dallas, Tex.

Disclosures: Author has nothing to disclose with regard to commercial support.

Received for publication Nov 6, 2019; revisions received Nov 6, 2019; accepted for publication Nov 7, 2019; available ahead of print Jan 24, 2020.

Address for reprints: Michael Mack, MD, 1100 Allied Dr, Plano, TX 75093 (E-mail: Michael.mack@bswhealth.org).

J Thorac Cardiovasc Surg 2020;159:1931-2

0022-5223/\$36.00

Copyright (c) 2019 by The American Association for Thoracic Surgery

https://doi.org/10.1016/j.jtcvs.2019.11.038
}

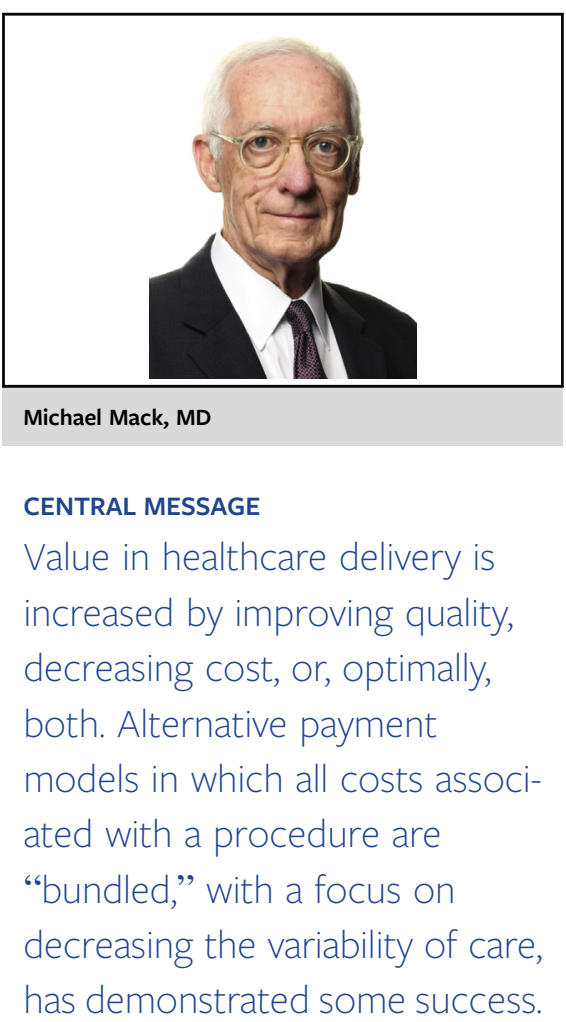

procedure" through 90 days after it. The reason for the 90-day global period is that a substantial portion of the currently uncontrolled cost incurred with procedures occurs in the postacute care setting. This is a "top down" model imposed by a government payer, although participation is voluntary at this point, versus the "partnership" model piloted in Colombia. It has also resulted in demonstrable cost savings and improvements in care.

In current fee for service healthcare delivery models, financial incentives drive care providers toward procedure performance. As healthcare systems transition to more value-based care in accountable care organization (ACO) models, a current euphemism for capitation, procedures move from being profit centers to being cost centers for providers, who now share financial risk. Nonetheless, either way, the bundling of procedures allows for more costeffective treatment models.

Most current value-based initiatives are focused on procedure performance by improving quality and controlling the cost of that procedure. However, the ultimate solution is likely to be focused on "disease management" rather than on "procedure management." By providing payment for the management of a disease, such as aortic stenosis, mitral regurgitation, or coronary artery disease, and not just the procedures performed to treat the disease, the value 
of healthcare to the patient is optimized. Although this may be a long-term goal of optimal healthcare delivery, the current efforts are directed mainly toward bundled payment for care approaches.

Umana and his team of stakeholders are to be congratulated on embarking on this ambitious program. Clearly this is a pilot study, and their next steps are to create diagnosis-related groups to avoid risk aversion by providers and to implement integrated care pathways to decrease variability in care. The next challenge is then to demonstrate scalability. Will this model work in other institutions with different providers and in different procedures and specialties? Is it translatable to other healthcare models in other countries? Although this remains to be seen, the authors are to be congratulated for putting their "toe in the water" by demonstrating the feasibility of implementing this bundled payment model as a potential solution to the problem of improving value in healthcare worldwide.

\section{References}

1. Umana JP. Bundled payment model implementation in a hospital in Colombia: challenges and key drivers of success. J Thorac Cardiovasc Surg. 2020;159: 1927-30.

2. Bundled Payments for Care Improvement (BPCI) Initiative. Center for Medicare and Medicaid Innovation. https://innovation.cms.gov/initiatives/bundledpayments/. Accessed November 3, 2019. 